\title{
The Latest Misfires in Support of the More Guns, Less Crime Hypothesis
}

\author{
Ian Ayres \& John J. Donohue*
}

\section{INTRODUCTION}

In our initial article-Shooting Down the More Guns, Less Crime Hypothesis ${ }^{1}$ - we reached two main conclusions: First, that there was no credible statistical evidence that the adoption of concealed carry (or "shallissue") laws reduced crime; and second, that the best, although admittedly quite imperfect, data suggested that the laws increased crime to the tune of $\$ 1$ billion per year (which is a relatively small number given the total cost of FBI index crimes of roughly $\$ 114$ billion per year). ${ }^{2}$ In their response to our article, John Lott, Florenz Plassmann, and John Whitley ("LPW") offer two sets of evidence in support of their view that that concealed carry laws are beneficial: first, they argue that some of our regression specifications really buttress their position; and second, they analyze some new county data for the period 1977-2000.

Their first method of proof fails because it simply overlooks - without even a single word of commentary! - the entire thrust of our paper that aggregated specifications of the effects of these laws are badly marred by "jurisdiction selection" effects. ${ }^{3}$ We did not misread these aggregated

* The authors thank LPW for sharing their data with us, Thomas Marvell and Michael Maltz for their helpful comments, Jennifer Chang, David Powell, and Nasser Zakariya for their outstanding research assistance.

1 Ian Ayres \& John J. Donohue III, Shooting Down the More Guns, Less Crime Hypothesis, 55 STAN L. REV. 100 (2003).

2. The average annual cost of the seven FBI Index I crimes over the 1977-97 period (in 1997 dollars) is $\$ 66$ billion for murder; \$8 billion for rape; \$22 billion for aggravated assault; $\$ 5$ billion each for robbery, auto theft, and burglary; and \$3 billion for larceny. These seven individual costs sum to a total of $\$ 114$ billion.

3. Selection effects can mar statistical analyses when the selected sample is taken as representative of a larger group even though it differs systematically from the larger group. Our paper showed that the aggregated regressions that Lott and Mustard prefer are frequently marred because they are confusing effects that apply in a few early-legalizing states with the effects that occur in all adopting jurisdictions. Therefore, in these aggregated regressions, there is a selection problem because some unrepresentative jurisdictions bias the estimated effects intended to capture the effects for all jurisdictions. We refer to this phenomenon as the "jurisdiction selection" effect. 
estimates, as LPW suggest; we simply showed that the LPW claims based on these aggregated estimates are inaccurate and misleading. The data at every turn rejects the idea that concealed carry laws passed in different jurisdictions have a uniform impact on crime. Therefore, the results of disaggregated regressions must, counter to LPW's claim, be taken as a more authoritative assessment of the overall impact of concealed carry laws. ${ }^{4}$

Their second method of proof fails because LPW seriously miscoded their new county data set in ways that irretrievably undermine every original regression result that they present in their reply. As a result, the new LPW regressions must simply be disregarded. Correcting LPW's empirical mistakes once again shows that the "More Guns, Less Crime" hypothesis is without credible statistical support.

Amidst all the tables and figures, all the regressions and tests of statistical significance, we strongly suspect that readers of our initial paper and the reply by LPW will be confused about the seemingly contradictory findings. Therefore, in this response we will try to clear away as much brush as possible to clarify exactly where the two papers disagree. Part I of this response shows why the aggregate specifications preferred by LPW are infected by a jurisdictional selection problem. Part II then shows how the more appropriate disaggregated specifications tend to show that concealed carry laws are associated with higher rates of crime. Finally, Part III then shows how this is all the more true if more years of data are correctly analyzed. ${ }^{5}$ The bottom line is that since all of their new evidence is fatally flawed, the LPW response essentially rests on interpreting some of our aggregated regressions in a way that we extensively argued should not be done. Since LPW never respond to our arguments on this point, we have not been moved to change any of the opinions that we previously advanced. ${ }^{6}$

4. Not surprisingly, because of the inadequacy of these crime models, there will be random influences that mar individual state-specific estimates. We contend that averaging the state-specific estimates will yield a more accurate picture than the aggregated estimates that LPW prefer, since the latter have all of the defects of the state-specific estimates, but lack their virtue of avoiding the severe selection bias.

5. Given the limited space we have been given for our reply, we are not able to provide a point by point refutation to all the items mentioned by LPW. In a separate paper, however, which is available on the web, we engage in a more detailed response to LPW. See Additional Comments on The Reply of Lott, Plassmann, and Whitley, at www.law.yale.edu/ayres/.

6. We do confess error on one small point, though. We stated in a footnote that the nightmare scenario of the unlawful shooting death of a sixteen-year-old Japanese exchange student on his way to a Halloween party was not mentioned by Lott and Mustard. See Ayres \& Donohue, supra note 1 , at 105 n.12. We should have said that, although they mentioned the incident in passing, Lott and Mustard inaccurately stated that the killing was not found to be "unlawful." See John R. Lott, Jr. \& David B. Mustard, Crime, Deterrence, and Right-toCarry Concealed Handguns, 26 J. Legal StUd. 1, 2-3 (1997).. Although the killer was not convicted of criminal homicide in that case, he was deemed to have acted tortiously and a substantial civil judgment was levied against him, as our footnote 12 noted. Ayres \& Donohue, supra note 1, at 105 n.12 Hence, the shooting was indeed "unlawful." Although 


\section{The Data Strongly ReJects Aggregate SPecifications}

Our initial paper provided three strong indications why states were likely to have very divergent impacts from passing the shall-issue law. First, a simple inspection of graphs suggested that states who by happenstance passed the law in the mideighties were likely to show a more beneficial impact from the law than states that passed later in the nineties. Second, one sees very different results if one looks at the early adopters versus those adopting after 1991. If one runs either the basic aggregated regressions on the period from 1991-1999 $\left(\mathrm{AD}^{7}\right.$ Table $\left.4^{8}\right)$ or the same regression over the full period while simply dropping the early passing states (as we discuss below), one sees a dramatically more deleterious impact of the law. Third, the wild gyrations in aggregate year-by-year impacts of the law as the composition of covered states changes suggests markedly different jurisdiction-specific impacts that should be controlled for by a more disaggregated regression specification.

\section{A. The Raw Crime Data Does Not Support a Claim That Crime Fell More in States Adopting Concealed Carry Laws}

Although our initial paper presents results from over 700 regressions, an important part of the story comes through in just a few pictures. Even a quick examination of our initial AD Figures $1 \mathrm{a}-1 \mathrm{f}^{9}$ shows that, for every crime category, the period from 1985-1992 was a bad spell. During this period crime was rising very rapidly, and, particularly for murder, this increase was noticeably greater for the states that never adopted concealed carry laws. Lott and Mustard's analysis has used statistical models to argue that the greater crime increases of the nonadopting states in this period resulted from their failure to adopt concealed carry laws. Indeed, they emphasize that others who have looked at the data over this same period have also found that the nonadopting states had greater crime increases than the adopting states. ${ }^{10}$

we had actually pointed this out to John Lott prior to the publication of the original Lott and Mustard paper, the error was not corrected.

7. To help readers identify the appropriate Tables and Figures, we will add "AD" and "LPW" prefixes to refer to tables and figures from the original Ayres \& Donohue paper and the Lott,Plassmann \& Whitley response in this issue, respectively.

${ }^{8}$ See Ayres \& Donohue, supra note 1, at [page] tbl.4.

${ }^{9}$ See id, at [page] figs.1a-1f.

10. While LPW contend that "most studies" have supported their work, it should be noted that they and David Mustard wrote five of the ten supporting studies that they cite in their first footnote. See John R. Lott, Jr., Florenz Plassmann \& John Whitley, Confirming More Guns, Less Crime, 55 StAn. L. Rev 100 (2003). Of the remaining four studies, the author of one-Michael Maltz - strongly insists that there is no credible evidence to support the more guns, less crime thesis, E-mail from John Donohue, Professor, Stanford Law School, to Michael Maltz, Professor, Department of Criminal Justice, University of Illinois at Chicago (Jan. 19, 2003); see also infra note 45, and the other three studies look only at the period through 1992 and/or use only the aggregated models 
However, the story changes after 1992. Crime starts falling everywhere, and it falls even more in the nonadopting states than in the adopting states. This is inconvenient for the Lott and Mustard hypothesis. We have argued that the initial Lott and Mustard study - relying on data that ended in 1992 — only came to the conclusion that it did because the immense crack-induced crime epidemic of the late 1980s hit states with large urban centers harder than the more rural, more Republican states that adopted concealed carry laws during this period. When the crack problem subsided, the nonadopting states, which had previously looked bad relative to the adopters, began looking much better. In the early 1990s, violent crime was substantially lower in the eight states that adopted concealed carry laws in the 1980s than in the twenty-two states that had never adopted these laws (except for rape, which was about the same in the two sets of states in the early 1990s). By the end of the 1990s, violent crime was at the same level or lower in the twenty-two nonadopting states (and substantially lower for rape). We suspect that most independent scholars will now realize that the Lott and Mustard 1977-1992 regression results suffered from serious omitted variable bias, and that it was this bias that drove Lott and Mustard's initial findings.

Looking over the entire period from 1977-1999, crime fell more in states that did not adopt concealed carry laws than in states that did. This is true for every crime category, except murder where there was essentially no difference in the change in crime rates in adopting and nonadopting states ${ }^{11}$.

\section{B. Using Aggregate Regressions, the Estimated Effect of Concealed Carry Laws in Later Adopting States Suggests a Highly Deleterious Impact}

To confirm that the early legalizers look very different from the late adopters, we reran our original $\mathrm{AD}$ Table $3^{12}$, which presents the basic aggregated regressions that LPW favor, while simply dropping out the early legalizers from the analysis (states adopting concealed carry laws prior to 1992). If concealed carry laws really did have the crime-reducing effect that

that we show to be problematic. Moreover, a sizeable array of other studies has also raised considerable doubts about the more guns, less crime hypothesis. We cited five of them in footnote 3 of our article, but there are others and more on the way. The latest of which we are aware is Tomislav V. Kovandzic \& Thomas B. Marvell, Right-to-Carry Concealed Handguns and Violent Crime: Crime Control Through Gun Decontrol?, available at http://papers.ssrn.com/paper.taf?abstract_id=321820. This paper uses panel data for 58 Florida counties from 1980 to 2000 to examine the effects on violent crime from increases in the number of people with concealed carry permits, rather than relying purely on a dummy measuring the presence of a concealed carry law. The authors "find little evidence that the law reduces or increases violent crime." Id., at 2.

11 See Ayres \& Donohue, supra note 1, at [page] figs.1a-1f, and id.,at [page] tbl.1, line 2, which present a simple panel data model with state and year fixed effects and no other explanatory variables.

${ }^{12}$ See id. at [page] tbl.3. 
they claim, it should show up when we simply drop out the pre-1992 early legalizers (a total of eleven jurisdictions under Vernick coding and twelve under Lott coding). ${ }^{13}$

However, doing so for the state data with and without state fixed trendswhich we present as Table 1 in this reply ${ }^{14}$ - reveals overwhelmingly positive coefficients suggesting large and statistically significant increases in crime. It would be hard to find a set of regressions results that were less supportive of the more guns, less crime hypothesis. All the evidence correlates concealed carry laws adopted after 1991 with higher rates of crime. Of course, the positive estimates are probably unrealistically large in these modified regressions for the same reason that unrealistically large negative coefficients were obtained by Lott and Mustard in their original analyses that ended in 1992: nonpassing states in the early period had a bigger run up in crime induced by the problem of crack, which made the adopting states look good by comparison, but when crime started falling in the 1990s it fell more in the nonadopting crack-plagued states making the adopting states of the 1990s look worse than they probably really were.

In light of the evidence that aggregated regressions of the type that Lott and Mustard favor yield estimates that the concealed carry laws overwhelmingly increased crime for states adopting after 1991 (when we simply drop the pre-1992 adopters). LPW will have to take their choice, either the differences are real, in which case the post-1991 concealed carry laws are driving up crime, or they are spurious, resulting from the influence of crack or some other extraneous factor that remains uncontrolled for in their models. In either event, we have further support for the view that the aggregated results are improperly combining very different estimated effects across the adopting states (and perhaps more evidence that crack cocaine drives the ostensible declines in crime in the early legalizing states).

13. Thomas Marvell has also pointed out that he has some disagreements with both the Lott and Vernick coding of the dates of passage of concealed carry laws for six states. He indicates that the proper dates for these six are: Louisiana (96), Maine (80), New Hampshire (94), Texas (95), Utah (95), and West Virginia (88). E-mail from John Donohue, Professor, Stanford Law School, to Thomas Marvell, Justec Research (Mar. 5, 2003). Moreover, Marvell states that neither North Dakota nor Indiana has a true shall-issue law, since both laws allow for discretionary refusals to award concealed carry permits. Id. Fortunately, the various different codings of dates of adoption of the concealed carry laws seem not to heavily influence any of the findings.

${ }^{14}$ See infra tbl.1. 
C. The Serious Selection Effect Occurs in the Aggregated Models Because in the First Few Years After Adoption all Adopting States Enter into the Estimated Effect of the Law, but Successively Fewer States Enter into the Longer Term Effects; Steps that Address the Selection Effect Problem Invariably Undermine the Lott and Mustard Hypothesis

The serious flaw in the aggregated estimates of the effect of concealed handguns using the Lott and Mustard-type regressions can be seen by examining the year-by-year estimates of the effects of concealed carry laws in AD Figures 3a-3i. ${ }^{15}$ These figures essentially highlight a twelve-year period extending from eight years prior to adoption to three years after adoption for which relatively complete data is available for all of the states adopting concealed carry laws. ${ }^{16}$ Looking at that period for all nine crime categories leaves one with no reason to think that these state laws lowered crime.

Three full calendar years after adoption, visual inspection suggests two patterns: First, for murder, robbery, property crime, auto theft, burglary, and larceny, crime is above the pre-passage low that occurred two or three years prior to adoption (suggesting only a regression to the mean phenomenon); 17 and, second, for violent crime, rape, and aggravated assault, crime simply continues along a prepassage trend, suggesting no effect. Outside the shaded area of these figures, one sees unreliable movements in the estimated effects from which LPW try to tell a story of law-induced drops in crime. Rather than providing useful information about the impact of these laws, these unreliable movements are the product of selection effects as later-adopting states increasingly drop out of the postpassage estimates (as shown in AD Table $7^{18}$ ).

The wild gyrations in the year-by-year estimates in the later years are

15. See Ayres \& Donohue, supra note 1, at [page] figs.3a-3i. The year-by-year estimates are temporally disaggregated and allow the data to choose the yearly pre and postadoption crime patterns controlling for state and year fixed effects, rather than imposing the greater structure of the dummy variable, spline, or hybrid models. All four of these approaches assume that the response to the law is identical for each adopting jurisdictionthe jurisdictional aggregation assumption-which leads to only a single estimated effect across all jurisdictions (at any point in time). This assumption is rejected by standard statistical tests, which explains why the state-specific estimates vary so much across jurisdictions, and why jurisdictional aggregation can be so problematic when not all states influence a particular estimated effect at a certain point in time (the selection effect problem).

16. We have complete data for all adopting jurisdictions over the period eight years before to three years after adoption with only one exception - there is no data for Maine in the period from eight to five years prior to adoption using the Vernick coding of the date of adoption of the concealed carry law. If we do not use the Vernick coding, though, we have complete data for all adopting jurisdictions over that entire period.

17. LPW properly consider crime rates that merely return "to their prelaw lows" to be evidence of mean reversion. See Lott, Plassmann \& Whitley, supra note 10, at 117. For murder and robbery, the reversion is incomplete since after three years, crime remained above the low in the three years prior to adoption.

${ }^{18}$ Ayres \& Donohue, supra note 1, at [page] tbl.7 
solely the product of the changing mix of states being tested. The reported results for eleven or more years after passage measure the results of only Maine, North Dakota, South Dakota, Utah, and Florida. The main payoff of these graphs is again just to show that any aggregated analysis is flawed. Disaggregated (state specific) analysis is necessary to see the real variation in crime that the data is trying to imperfectly reflect in the aggregated year-specfic analysis. To control for this jurisdiction selection effect in a more systematic way than our visual inspection of AD Figures 3, we ran a regression that limits the estimate of the effect of the law to the period with the most complete data from eight years prior to three years after adoption. When this is done, the concealed carry laws lead to increases (or no effect) in violent crime, murder, robbery, property crime, auto theft, burglary, and larceny. No clear picture emerges of the effect on the other two crimes (rape and aggravated assault) since some models predict increases or no effect, and others predict decreases ${ }^{19}$.

LPW point to our initial AD Figures $3 \mathrm{a}^{20}$ (robbery) and $3 b^{21}$ (murder) as evidencing a drop in crime induced by the adoption of concealed carry laws, and completely ignore our argument that the apparent drop is purely the product of a selection effect. This is remarkable in that one usually expects a response to address the main arguments of the original paper, but even more so because of their one-sided invocation of the selection effect problem. Specifically, they explicitly try to take advantage of the selection effect to argue that the ostensible jump in the murder rate after thirteen years should not be taken as evidence against their thesis. Referencing this upward jump, they state:

The increase between years thirteen and fourteen is ... more apparent than real. The real 'increase' is actually not due to any sudden change in Maine's crime rates, but due to the fact that other states are included in calculating the crime rate for year thirteen, while only Maine is used for year fourteen. ${ }^{22}$

The specific point that LPW make is wrong in that Maine is not the sole state until the fifteenth year. In year fourteen Maine, North Dakota, and South Dakota all influence the estimated effect of the law. The general point they make, however, is correct, although they utterly fail to understand its importance. The selective dropping out of states from the estimated effect of the law generates all of the ostensible crime drop that they cheer for years fourthirteen (after adoption). To repeat their phrase, this effect is "more apparent than real." ${ }^{, 3}$ In their Section $1 \mathrm{C}$, they also try to credit the out-year data as evidence of a drop in rape and aggravated assault, but the same selection effect

${ }^{19}$ See Ayres \& Donohue, supra note 1, at [page] tbl.8.

${ }^{20} I d$. at [page] fig. $3 \mathrm{a}$.

${ }^{21} I d$. at [page] fig. 3 b.

${ }^{23} I d$.

22. Lott, Plassmann \& Whitley, supra note 10 , at 106. 
argument undermines this attempt. We would suggest that LPW take another look at two tables in our original paper: AD Table $7^{24}$, which illustrates how the sample of states driving the aggregated estimated effects shrinks dramatically four years after adoption; and $\mathrm{AD}$ Table $8^{25}$, which shows that when one looks at the period of most complete data from eight years before passage to three years after passage, there is considerable evidence of crime increase and no robust evidence of any decline associated with the adoption of a concealed carry law. ${ }^{26}$

This same jurisdictional selection effect mars all of the aggregate regression specifications. While the aggregated results (found either in $\mathrm{AD}$ Tables 10 and 11 for county data or AD Table 3 for state data ${ }^{27}$ ) may appear superficially supportive of the Lott and Mustard thesis in that murder, rape, robbery, and burglary seem to be dropping with the passage of the law (even as property crimes are rising), they are similarly the product of the serious jurisdiction selection effect problem that marred the AD Table 3 results $^{28}$ : once the late-adopting states drop out of the aggregated estimates, one is no longer comparing a consistent set of states across time.

But even if LPW were correct in ignoring the importance of this selection effect problem, the year-by-year analysis would still not provide solid support for the more guns, less crime hypothesis. Indeed, the picture that LPW paint of falling crime many years after adoption of concealed carry laws is not supported for four out of five violent crimes when the year-by-year estimates are generated while controlling for pre-existing state crime trends. To see this, Figures 1a-1e of this reply ${ }^{29}$ recreate the five violent crime graphs of $\mathrm{AD}$ Figure $3^{30}$ while super-imposing the year-by-year estimates that emerge when we control for state trends. The first thing to note is that, when one looks at the

${ }^{24}$ See Ayres \& Donohue, supra note 1, at [page] tbl.7.

${ }^{25}$ See id. at [page] tbl.8.

26. Of course, this is the answer to all of their claims in their Section 1D. The (temporally disaggregated but jurisdictionally aggregated) year-by-year breakdown-which they assert provides "a much more accurate picture of changing crime patterns"-actually shows why all the jurisdictionally aggregated models they rely on so heavily are misspecified. It is not, as LPW Figure 2 suggests that crime is dropping so sharply a number of years after passage, making a linear approximation inappropriate. It is because the selection effect of states dropping out of the aggregated estimated effect of the law leads to the misspecification. See Lott, Plassmann \& Whitley, supra note 10, at 107-10. Once again, AD Table 8 provides the evidence on the most consistent data comparing all states over the four years prior to passage and the three years after (and only missing Maine for the period from minus eight to minus five), and the evidence for the "More Guns, Less Crime" theory evaporates when apples and apples are being compared. See Ayres \& Donohue, supra note 1, at [page] tbl.8. Note that another way to address the selection effect problem is to look at the state-specific estimates, which again suggest the laws predominantly increase crime.

${ }^{27}$ See Ayres \& Donohue, supra note 1, at [pages] tbls.3, 10,11.

${ }^{28} I d$. at [page] tbl.3.

${ }^{29}$ See infra figs.1a-1f.

${ }^{30}$ Ayres \& Donohue, supra note 1, at [page] fig.3. 
period of most complete data (from eight year prior to three years after adoption of the concealed carry laws), controlling for state trends yields results that are either similar to the results without such controls or further strengthen the case against the more guns, less crime hypothesis. Second, even if one ignores the selection effect problem by relying on the results beyond three years after adoption, as LPW do, the year-by-year estimates show violent crime increases in four out of five cases when we control for state trends. Specifically, violent crime, rape, aggravated assault, and robbery show no sign of the drop in crime that LPW emphasize. ${ }^{31}$ Do these results signal massive increases in violent crime in the wake of adoption of concealed carry laws? Although the logic of LPW's analysis would dictate this conclusion, we would caution against that interpretation in light of the selection effect problem. Instead, point 1 seems sounder-controlling for state trends provides further ammunition against the more guns, less crime hypothesis over the period from eight years prior to three years after adoption of concealed carry laws.

In sum, there are many reason to be skeptical of the LPW assumption that concealed carry laws had an identical (dampening) effect on crime in every adopting jurisdiction. A simple inspection of graphs charting crime across time, our regressions excluding early adopters or limiting the analysis to the 1991-1999 period, and our year-by-year regressions all led us to conclude that modeling an aggregate state effect was inappropriate. The natural response is to estimate a less-constrained specification that allows the regression to test for state-specific impacts.

\section{The Disaggregated Regressions SHOW That CONCEALED CARRY LAWS TEND TO INCREASE CRIME}

We did just this: We ran regressions on the less constrained state-specific hybrid model. This jurisdictionally disaggregated model massively rejected the Lott and Mustard assumption of a uniform effect of the law across all states. 32

\footnotetext{
${ }^{31}$ The ostensible drop in crime beyond the third full year after adoption appears stronger for murder when controlling for state trends, as shown in Figure 1b. The bottom line is that the year-by-year results that LPW trumpet are not robust to the inclusion of state trends. If state trends should be included in the analysis, then either concealed carry laws increase every violent crime except murder, or the statistical models are generating spurious results (perhaps because of the omitted variable problem of crack, which had a greater impact on murder than any other crime. Thus, the potentially must unreliable result is the only one (of five) that supports the LPW thesis.

32. LPW do attempt to provide state-specific estimates, although they use a linearspline model, rather than our less constrained hybrid model. Since our statistical tests rejected this model, we found this choice puzzling. However, as we discuss below, they mis-defined some of their variables, which messed up all of their own regressions, so their claims about their state-specific spline models should be ignored (at least until all their errors are corrected).
} 
To be specific, standard statistical tests (measuring the better fit of the lessconstrained disaggregated regressions) formally rejected the aggregate specifications in AD Tables 10 and $11^{33}$ that Lott and Mustard prefer. Therefore, it is more appropriate to rely on the regressions estimating the more general state-specific estimates (AD Tables 12 and $13^{34}$ ). 35 These disaggregated regressions directly solve the jurisdiction selection problem because they do not attempt to combine the diverging impacts of different jurisdictions into a single estimate of the laws' impact.

When we estimated these state-specific effects, we found substantially less support for LPW's crime-reduction hypothesis. For every crime category, substantially more of the resulting state-specific estimates show estimated increases in crime following the adoption of these laws than show decreases (and the disparity is even greater if one limits the analysis to statistically significant estimates). Moreover, when these state-specific county estimates are converted into dollar values (AD Table $14^{36}$ ), the effect of adoption of concealed carry laws using our preferred hybrid model is to increase the overall cost of crime by roughly $\$ 1$ billion (AD Table $15^{37}$ ).

LPW suggest that our disaggregated hybrid model may be mis-specified if there is a downward curve in crime rates following adoption of concealed carry laws ${ }^{38}$. Ironically, this problem would be, if anything, more severe for their spline specification, as opposed to our less constrained hybrid specification. But the correct response to the potential problem of fitting a line to a curve is

${ }^{33}$ Ayres \& Donohue, supra note 1, at [page] tbls.10, 11.

${ }^{34}$ Id. at [page] tbls.12, 13.

35. This jurisdictional selection effect problem undermines their similar LPW Table 1 and 2 analyses. See Lott, Plassmann \& Whitley, supra note 10, at [page] tbls.1,2. For example, LPW Table 1 averages together the monetary impact of five different nowdiscredited aggregate specifications together with two preferable state-specific specifications. Id at [page] tbl.1. Nonetheless, LPW seem to think that all seven estimates (the five aggregated estimates that we have rejected as well as the two disaggregated statespecific estimates that we prefer) are equally valid, which leads them to take the average of the seven estimates (four of which show crime decreases and three of which show crime increases). We could hardly agree with this approach for all the reasons we have set forth in our paper. If one has five unreliable estimates and two better ones, is it really good practice to take the average of all seven numbers as your best estimate? The bottom line is that four of the five aggregated estimates show declines in crime, while the two state-specific estimates that avoid the problems of the aggregated models show increases in crime of over $\$ 1$ billion per year. Until LPW can convince us why we should give equal weight to statistical models that are rejected by standard statistical tests and that show obvious signs of mis-specification because of the serious selection effects as states drop out of the postpassage estimates, we simply have no reason to average across the seven estimates. The two state-specific estimates both show that concealed carry laws are associated with increased crime, and these estimates are clearly preferable to the flawed aggregated estimates.

${ }^{36}$ Ayres \& Donohue, supra note 1, at [page] tbl.14.

${ }^{37}$ Id. at [page] tbl.15.

${ }^{38}$ See Lott, Plassmann \& Whitley, supra note 10, at 109 fig.2. 
not to assume away the problem by fiat (by constraining the direct effect to be zero, as their spline model does) but rather to go to a less constrained specification and let the data tell us whether the implicit constraints of the linear hybrid specification are rejected. The natural next step is a second-order hybrid specification, which estimates a direct/dummy, linear/spline, and quadratic spline effect. We already did this in our original paper. In footnote 106 , we discussed a quadratic hybrid regression that we ran to test whether the constraints of the linear hybrid were legitimate, stating:

It is possible, of course, to estimate even less constrained specifications that admit the possibility of higher order impacts. And indeed, we estimated a disaggregated quadratic hybrid that is identical to the disaggregated hybrid discussed above but which includes a pre-passage quadratic term and a postpassage quadratic spline term. Estimating this quadratic hybrid specification allowed us to test (1) whether the implicit restrictions of the (linear) hybrid are rejected by the less constrained specification and (2) whether the results of the (linear) hybrid were robust to the less constrained specification. We found that the (linear) hybrid's implicit assumption of no quadratic post-passage effect was not decisively rejected in that only 49 of the 216 coefficients were statistically different than zero (although the quadratic spline effects were jointly different than zero in eight of the nine regressions). But the basic results of the (linear) hybrid analysis discussed in the text remain unaltered: Calculating the net annualized 5-year impact, we continued to find that the vast majority of the statistically significant impacts were positive (48 vs.20). ${ }^{39}$

In other words, our state-specific county data model (with Lott coding of the concealed carry jurisdictions) continues to show substantially more statistically significant increases in crime than decreases when a quadratic hybrid model is used. Since our above-quoted footnote discussion on this point seems not to have been adequate, we present more details of this approach in Table $2^{40}$ below. 41 As the table reveals, four states show a statistically significant increase in violent crime while only two show a statistically significant decrease; five states show a statistically significant increase in murder, while only one state shows a statistically significant decline. In fact, every crime category of this quadratic hybrid specification shows more positive than negative five-year impacts. Moreover, the population-weighted average of the crime effects for the twenty-four jurisdictions is uniformly positive. In particular, the annualized five-year impact of the law was a 3.7\% increase for violent crime, and a $7.7 \%$ increase for murder ${ }^{42}$.

39. Ayres \& Donohue, supra note 1, at 143-44 n.106.

${ }^{40}$ See infra tbl.2.

41. Table 2 indicates that $22.7 \%$ of the postpassage quadratic effects were statistically significant, although only $6.9 \%$ of the postpassage quadratic effect had negative statistically significant curvature of the kind that LPW posited in LPW Figure 2. Lott, Plassman \& Whitley, supra note 10, at 109 fig.2. Even after we allow the data to choose the degree of curvature, we still find positive and statistically significant direct effects for $10.6 \%$ of postpassage direct effects $(23 / 216)$.

${ }^{42}$ See infra tbl.2. 
When we tally up the estimated annualized dollar impact of the law on crime (as we did in our original AD Table $14^{43}$ ), we find that moving to this less constrained quadratic-hybrid specification increases the estimate of the harm associated with adoption of concealed carry laws. AD Table 14 uses the linear hybrid specification estimated that concealed carry laws had increased the cost of crime in the passing states on an annualized basis of roughly a billion dollars. However, Table 2 here almost doubles this amount suggesting that concealed carry laws increase crime costs annually by $\$ 1.97$ billion. ${ }^{44}$ Thus, while we are not sure the quadratic hybrid is an improvement over the linear hybrid state-specific models (since the constraints of the latter model were not strongly rejected), the use of the quadratic hybrid model responds to the LPW claims of linear hybrid mis-specification and provides even stronger evidence against the "More Guns, Less Crime" hypothesis.

\section{The LPW Regressions on the New County Data SET ARE AlL Fatally FlaWed By SERIOUS CODING PROBlemS}

LPW emphasize a series of regressions run on a new county data set that extends the data series substantially further forward to the year 2000. They argue, in sharp contrast to our article, that adding even more data buttresses the crime-reduction hypothesis. But, putting aside lingering concerns we have with the new county data, ${ }^{45}$ there are reasons to be immediately suspicious about the

${ }^{43}$ Ayres \& Donohue, supra note 1, at [page] tbl.14.

44. Paralleling AD Table 15, Ayres \& Donohue, supra note 1, at [page] tbl.15, the estimate of increased crime persists regardless of the significance filter we impose: no filtering, $\$ 1.9$ billion; $10 \%$, $\$ 1.4$ billion; 5\%, $\$ 945$ million; and 1\%, $\$ 796$ million.

45. Following Michael Maltz, we have been concerned about relying on any analysis that uses county crime data, particularly if the data extends across the period before and after 1993 (when the reporting agency substantially changed its data collection method). See Ayres \& Donohue, supra note 1, at [pages for the text accompanying note80??] . But LPW claim that we have misread Maltz, and that Maltz did not assert that reliance on the county data set was unwise. Both claims are false. Indeed, we showed our statement and the LPW response to Michael Maltz, and he rejected the LPW allegation. Maltz said that, if anything, our paper actually understated the Maltz and Targonski criticism of the county-level data: they view the county data to be severely flawed overall, and "especially if" (not "only if") one extends the data across the break in the series that occurred in 1994. E-mail from John Donohue, Professor, Stanford Law School, to Michael Maltz, Professor, Department of Criminal Justice, University of Illinois at Chicago (Jan. 19, 2003). In response to LPW's claim that the measurement problems are no worse in the county data than in the state data, Maltz replies: "both state- and county-level data are affected, but state-level data are affected much less profoundly." IId.

LPW also contend that Maltz and Targonski have "no discussion of a post 1992 break in the quality of data." Lott, Plassmann \& Whitley, supra note 10, at 125. Maltz again disagrees: "We noted: "

The 1994 NACJD codebook (ICPSR dataset 6669) explicitly notes this in a major heading, 'Break in Series,' and describes the new imputation procedure it began using in 1994. It goes on to state, These changes will result in a break in series from previous UCR county-level files. Consequently data from earlier year files should not be compared to data from 1994 
claim that LPW make in their response that adding more years of data would strengthen the more guns, less crime hypothesis. As our original AD Tables $1 \mathrm{a}-1 \mathrm{f}^{46}$ showed, crime tended to drop more in the nonadopting states in the 1990s than in adopting states, and regressions run only on the data from 19911999 found that the vast bulk of the coefficients were positive (although only the effects for property crimes were statistically significant ${ }^{47}$ ). Thus, one would normally expect that adding more data would weaken the Lott and Mustard findings rather than strengthening them as LPW contend in their response. This puzzle was resolved when they shared their data with us. We found that they had made a number of coding errors, which we describe below. Correcting these errors, which contaminated every regression that was run for their reply to our paper, had a profound effect on their estimates and restored the conclusions that concealed carry laws were associated with increases in crime (or no effect) for all crime categories.

Note that the new regressions presented by LPW differ from ours in two main ways. First, they extend their county data to the year 2000. Second, they control for region-year effects (as opposed to a uniform national fixed effect). To illustrate the nature of the errors we found in their data, and the importance of these errors to their results, first consider their LPW Table $3 \mathrm{a}^{48}$, which presents the estimated impact of concealed carry laws on crime using the dummy, spline, and hybrid models on their expanded county data set. (This is their very first table presenting new regression evidence). Unfortunately, LPW miscoded many of the region-year dummies. For example, for Pennsylvania in 1997-2000, no region-year dummies were assigned. 49 When we corrected this mistake and others like it, 50 the results were completely reversed. For example,

and subsequent years because changes in procedures used to adjust for incomplete reporting at the ORI or jurisdiction level may be expected to have an impact on aggregates for counties in which some ORIs have not reported for all 12 months.Id. "In other words," Maltz continues, "Lott refuses to acknowledge that his entire county-level analysis in the second edition of his book is faulty." Id.In response to the LPW statement-"Nor do Maltz and Targonski provide any evidence that state level data are more dependable than county level data."-Maltz replies: "We do so in our response to his response to our paper." Id. At the least, it must be conceded that there is no truth to the LPW claim that we misinterpreted Maltz's views.

${ }^{46}$ Ayres \& Donohue, supra note 1, at [page] figs.1a-f.

${ }^{47}$ See id. at [page] tbl.4.

${ }^{48}$ Lott, Plassmann \& Whitley, supra note 10, at [page] tbl.3a.

49. In the LPW data set, there is a variable called NE trend that is used to generate the region-year effects for every county in the Northeast region, which includes Pennsylvania. For every county in that region, the crime rate observation is assigned an NE trend value for the particular year, which would be 1990 in the year 1990, 1991 in the following year, etc. For Pennsylvania, the NE trend variable shows zero for each year 1997-2000, which essentially knocks out the region-year dummy for all the Pennsylvania counties for that fouryear period. Thus, the NE trend value for the Pennsylvania counties drops down from 1996 in 1996 to zero in the next four years.

50. For 1999 and 2000, Alaska's region-year dummies had errors similar to Pennsylvania's. Moreover, Hawaii was excluded from all five of the regions used in their 
the top panel of Table $3^{51}$ shows our replication of LPW Table 3a. Note that for the dummy variable model, they find that murder, rape, and robbery all show statistically significant declines. The bottom panel of Table $2^{52}$, which corrects the errors in LPW Table 3a, now reveals that the only statistically significant results in the dummy model are the three increases in property crime, auto theft, and larceny. LPW described their LPW Table 3a spline results as follows: "The change in trends is statistically significant at least at the $10 \%$ level for all individual violent crime categories for the spline estimates, implying that murder, rape, and robbery fall by over $2 \%$ per year during each additional year that right-to-carry laws are in effect." ${ }^{, 53}$ However, our corrected estimates find that none of the estimates for the violent crime categories are significant when using the spline model. In fact, the spline model does not generate a significant effect for any crime category.

These serious data errors infect every regression presented in the LPW response. Consequently, researchers and policy makers should not rely on any of the new regressions that LPW present in their reply.

\section{CONCLUSION}

It is now possible to clarify the existing differences between us and LPW. ${ }^{54}$ While we emphasized the severe selection effect problem of estimating the effects of concealed handguns by aggregating across all the adopting jurisdictions, LPW simply ignore this concern. When they contend that we have "misread" our own results, it is because they cite the jurisdictionally

region-year analysis.

Massachusetts's shall-issue law dummy variable was improperly coded as "missing" for 1999 and 2000 observations. Since Massachusetts did not have a shall-issue law, all counties in the state should have a shall-issue dummy variable value of zero for each year. Similarly, the before and after trend variables for Massachusetts in 1999 and 2000 should equal 0; instead, they were also improperly coded as "missing."

We also noticed that LPW's shall-issue dummy coding implied that they considered Idaho to have passed its shall-issue law in 1991, but in coding their year-by-year dummies for use in their year-by-year analysis they treated Idaho as passing the law in 1990, which is the date of passage that we have been using. See Ayres \& Donohue, supra note 1, at [page] tbl.1. The table we present as the "corrected" version of LPW Table 3a, see infra tbl.3a, has not changed their coding of Idaho passing in 1991.

${ }^{51}$ See infra tbl.3.

${ }^{52}$ See infra tbl.2.

${ }^{53}$ Lott, Plassmann \& Whitley, supra note 10, at 114.

54. LPW make a number of small points that are probably a distracting waste of time for the readers. For example, LPW take issue with our claim that the United States is exceptional in its rate of lethal violence. We of course were referring to the advanced industrial countries that one ordinarily considers to be the natural comparison group for the United States, for which the claim is certainly true. LPW note that a number of developing countries have higher rates of lethal violence than the United States, but, in any event, the issue simply has no bearing on what the impact of concealed carry laws is on crime in the United States. 
aggregated regression estimates that we showed were flawed, and continue to pin their "More Guns, Less Crime" hypothesis on this flawed estimation approach. Indeed, if one accepts our view on this point, one has to jettison virtually their entire paper, which probably explains why they did not respond to the issue. LPW present twelve figures and thirteen tables in their paper that offer estimates of the effect of concealed carry laws on crime, and of these, every one but LPW Table $6^{55}$ and Appendix Table $4^{56}$ is unreliable because they rely on the discredited jurisdictional aggregation assumption. Moreover, every new regression on LPW's extended county data set is fatally flawed by coding errors that conveniently support their thesis, so readers must be careful to disregard every regression finding that they ran (that is, everything from LPW Table 3 on and LPW Figure 4 on).

LPW charge that Ayres and Donohue have misread their results, but only because they ignored our discussion of the dangers of aggregation so well documented in our AD Figures $3 \mathrm{a}-3 i^{57}$ and our AD Tables 7 and $8^{58}$. The bottom line is that the best evidence suggests overall small increases in crime associated with adoption of concealed carry laws, but there are enough factors to counsel caution in making strong conclusions. One such concern is the fact that the most consistently strong results suggest increases in property crime, even though the theoretical link between these laws and property crime hikes is obscure.

In the wake of some of the criticisms that we have leveled against the Lott and Mustard thesis, John Lott appeared before a National Academy of Sciences panel examining the plausibility of the ore uns, ess rime thesis and he presented them with a series of figures showing year-by-year estimates that appeared to show sharp and immediate declines in crime with adoption of concealed carry laws. David Mustard even included these graphs in his initial reply to the Donohue paper in the Brookings book that LPW refer to repeatedly in their current reply. But Donohue privately showed Mustard as well as the Brookings editors that the graphs were the product of coding errors in creating the yearby-year dummies, and in the end Mustard conceded and withdrew them from his comment on Donohue. Now LPW respond to our paper with an array of regressions that purport to support their thesis, but again are utterly flawed by similar coding errors. We previously made no mention of the initial National Academy of Sciences/Brookings response error, since we know how easy it is to make mistakes in doing this work. But for the second time Lott and coauthors have put into the public domain flawed regression results that happen to support their thesis, even though their results disappear when corrected. Claiming we misread our results in the face of such obvious evidence to the

\footnotetext{
${ }^{55}$ Lott, Plassmann \& Whitley, supra note 10, at [page] tbl.6.

${ }^{56} I d$. at [page] tbl.4.

${ }^{57}$ Ayres \& Donohue, supra note 1, at [page] figs.3a-3i.

${ }^{58}$ Id. at [page] tbls. 7,8 .
} 
[Vol. XX:nnn

contrary and repeatedly bringing erroneous data into the public debate starts suggesting a pattern of behavior that is unlikely to engender support for the Lott and Mustard hypothesis. We feel confident concluding that we have indeed shot down the "More Guns, Less Crime" hypothesis. 59 Perhaps LPW can now assist in laying it to rest.

59. As emphasized in our original article, we are not necessarily replacing it with a "More Guns, More Crime" result. Rather we emphasized that reasonable researchers could embrace one of three possibilities:

i). concealed carry laws tend to increase crime

ii). concealed carry laws don't have any effect or at this date have an unknown effect; and

iii). concealed carry laws have heterogeneous effects - increasing crimes in most jurisdictions but decreasing it in some. 
Figure 1a: Violent Crime - Normalized Effect by Year Relative to Adoption (Vernick Coding)
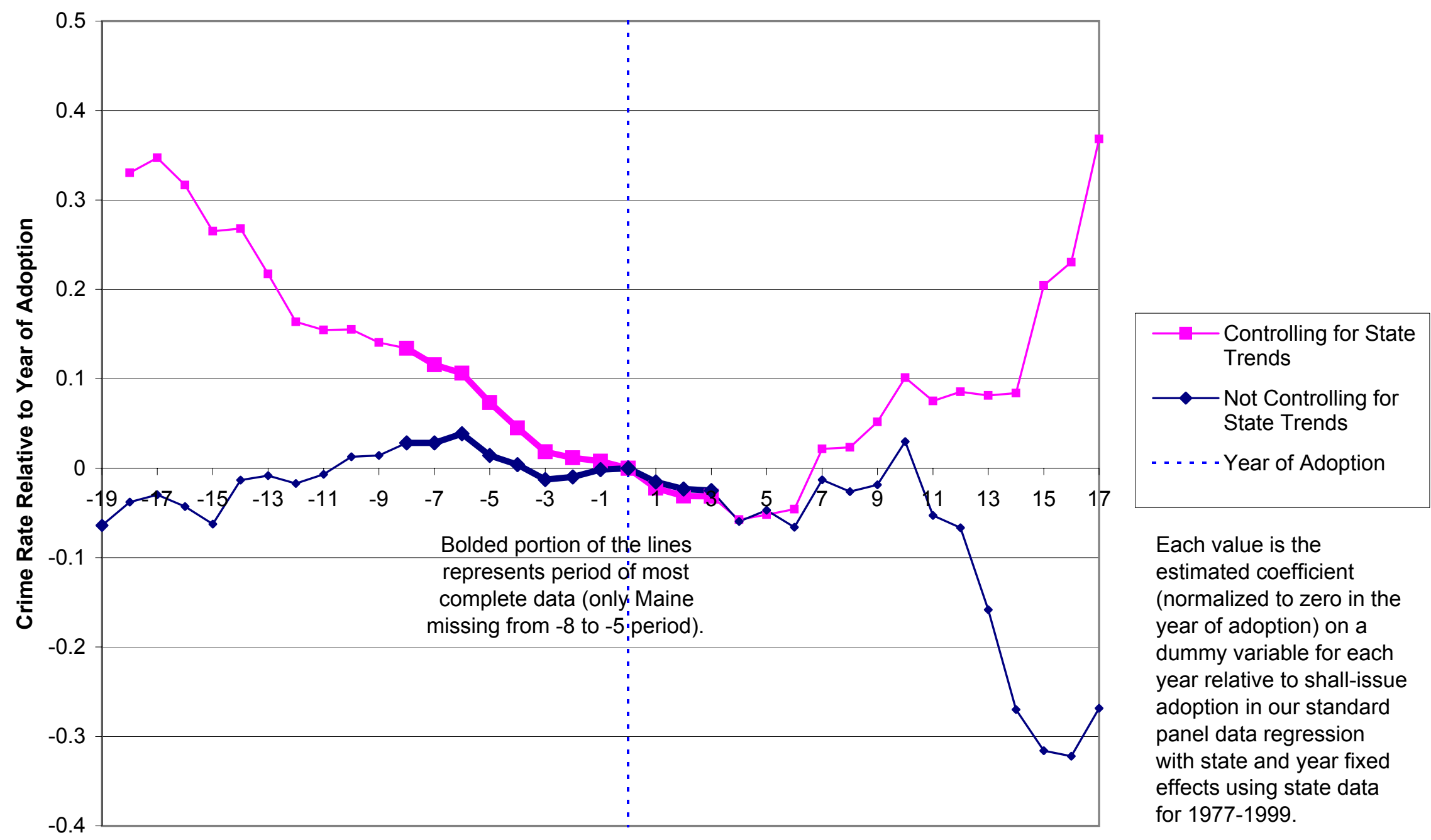

Each value is the

estimated coefficient (normalized to zero in the year of adoption) on a dummy variable for each year relative to shall-issue adoption in our standard panel data regression with state and year fixed effects using state data for 1977-1999. 
Figure 1b: Murder - Normalized Effect by Year Relative to Adoption (Vernick Coding)

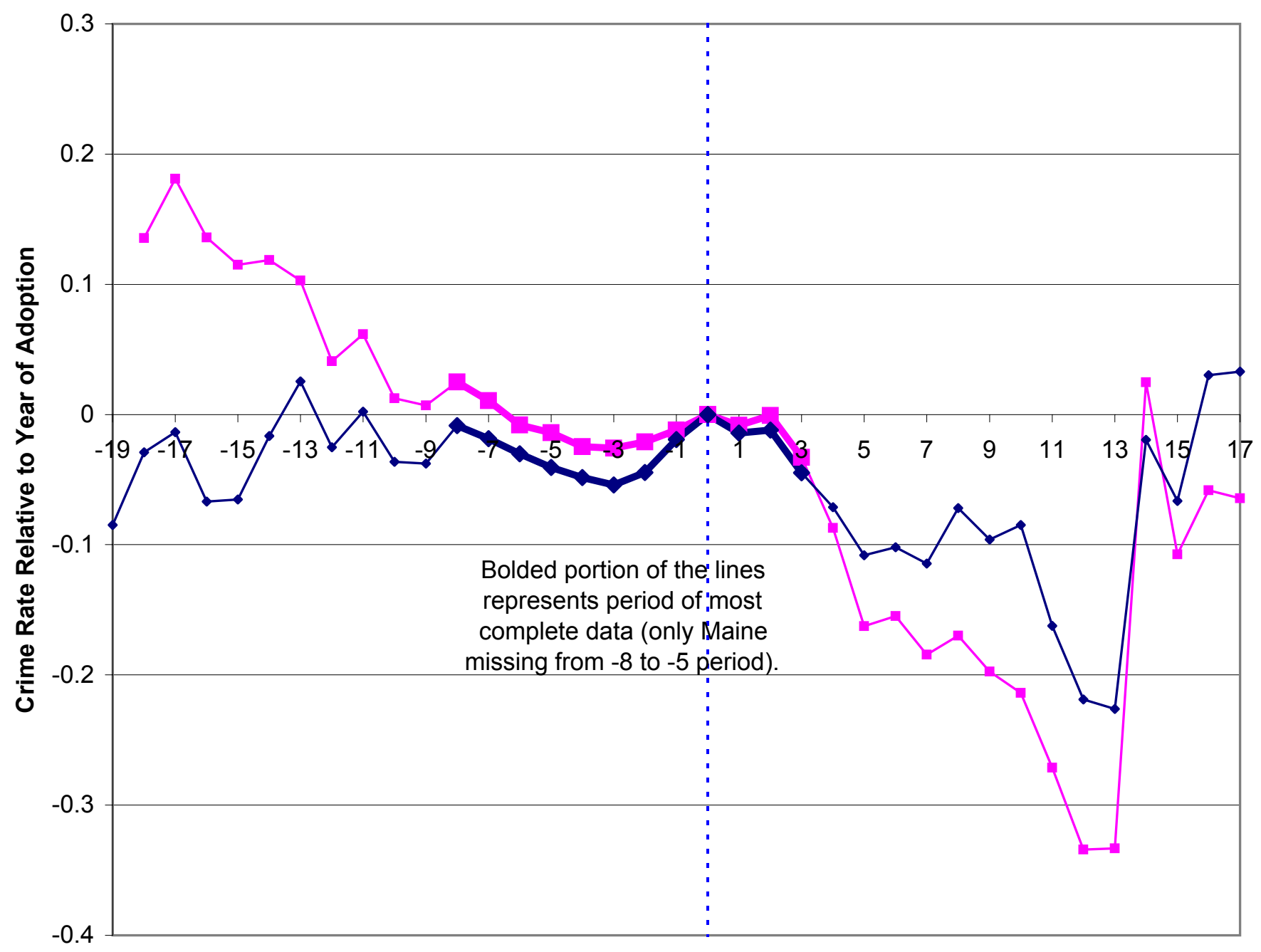

-Controlling for State Trends

$\longrightarrow$ Not Controlling for State Trends

- . - . - Year of Adoption

Each value is the estimated coefficient (normalized to zero in the year of adoption) on a dummy variable for each year relative to shall-issue adoption in our standard panel data regression with state and year fixed effects using state data for 1977-1999. 
Figure 1c: Rape - Normalized Effect by Year Relative to Adoption (Vernick Coding)

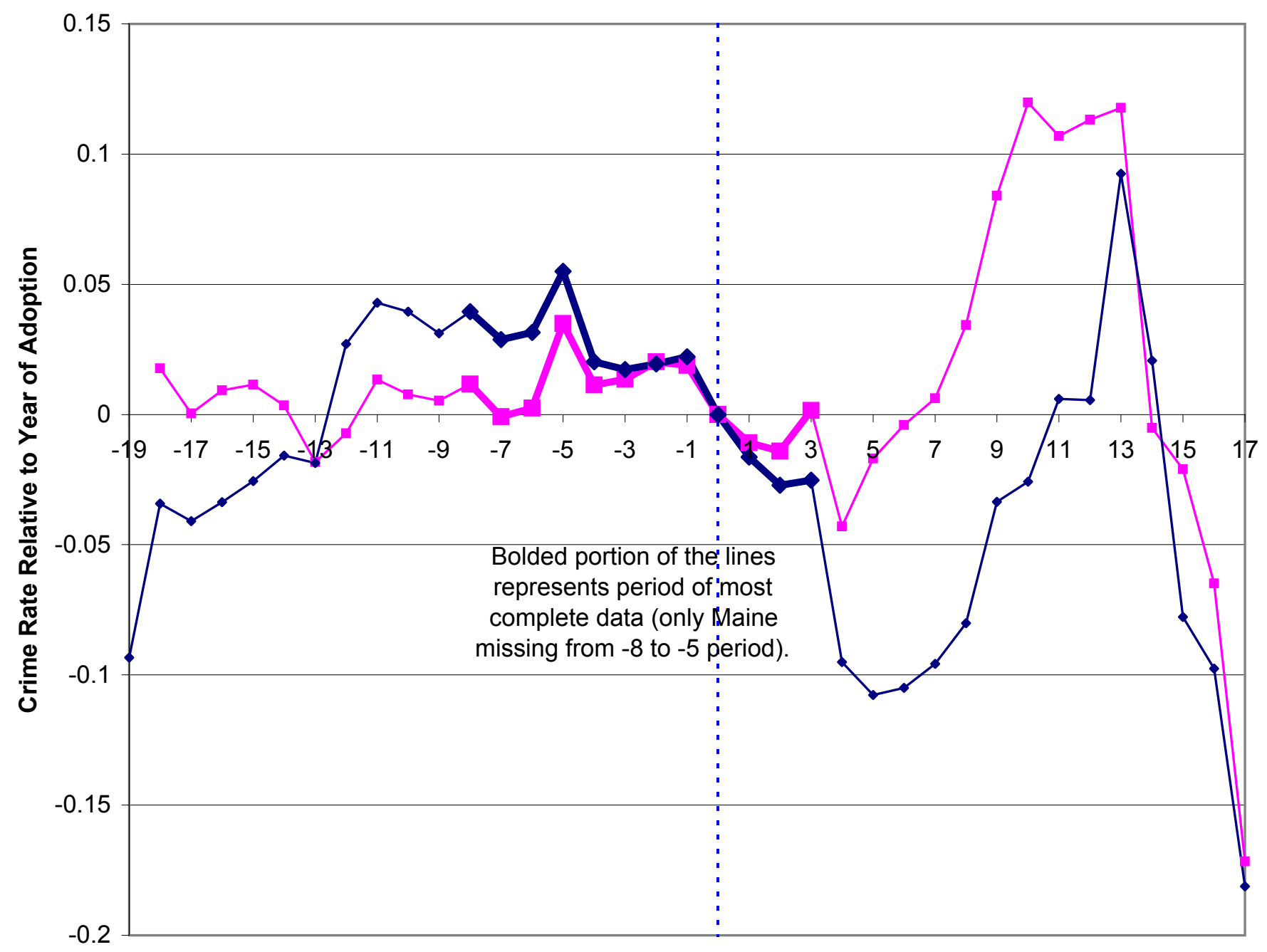

- Controlling for State Trends

$\longrightarrow$ Not Controlling for State Trends

- . . . - - Year of Adoption

Each value is the estimated coefficient (normalized to zero in the year of adoption) on a dummy variable for each year relative to shall-issue adoption in our standard panel data regression with state and year fixed effects using state data for 1977-1999. 
Figure 1d: Aggravated Assault - Normalized Effect by Year Relative to Adoption (Vernick Coding)
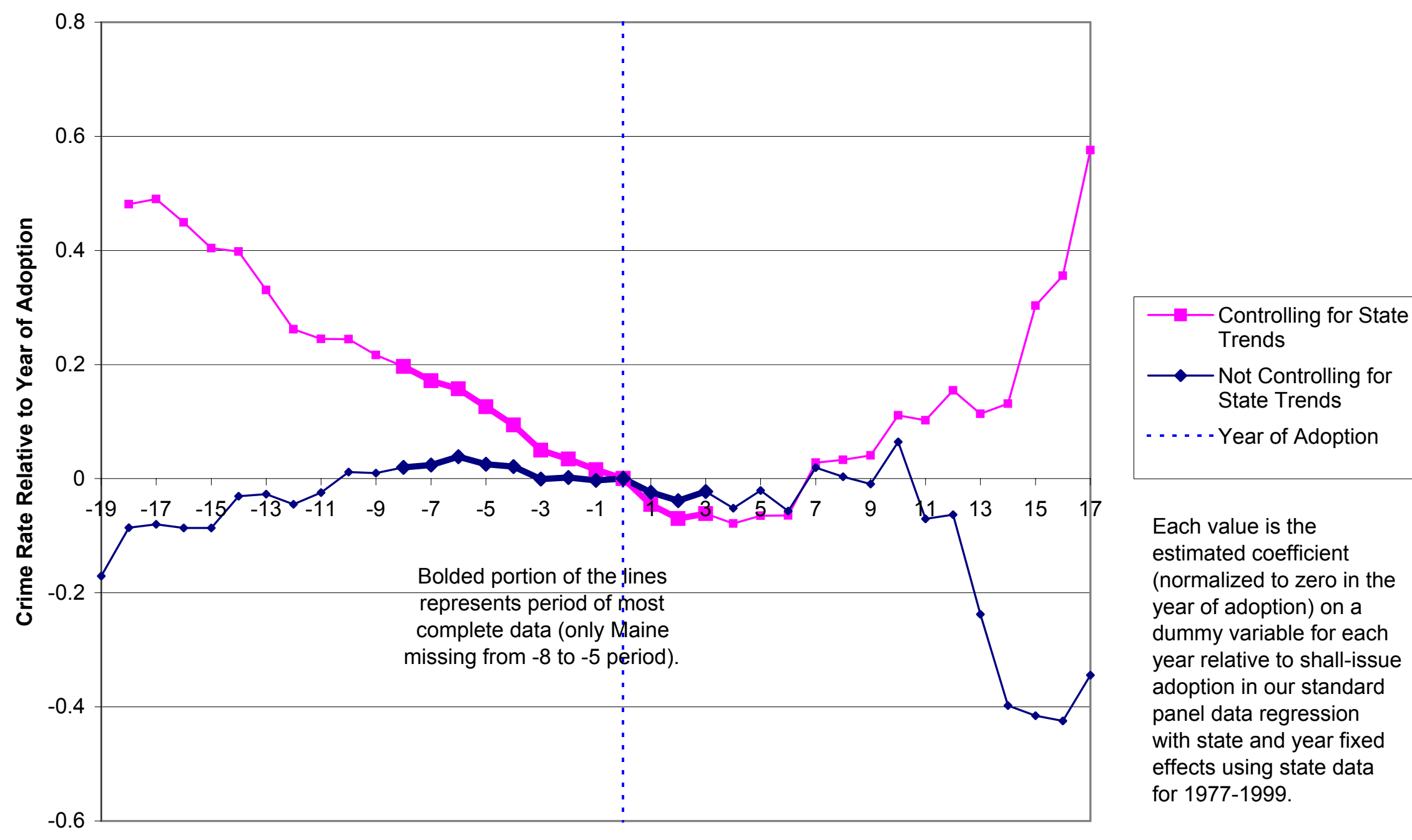

Each value is the estimated coefficient (normalized to zero in the year of adoption) on a dummy variable for each year relative to shall-issue adoption in our standard panel data regression with state and year fixed effects using state data for 1977-1999. 
Figure 1e: Robbery - Normalized Effect by Year Relative to Adoption (Vernick Coding)

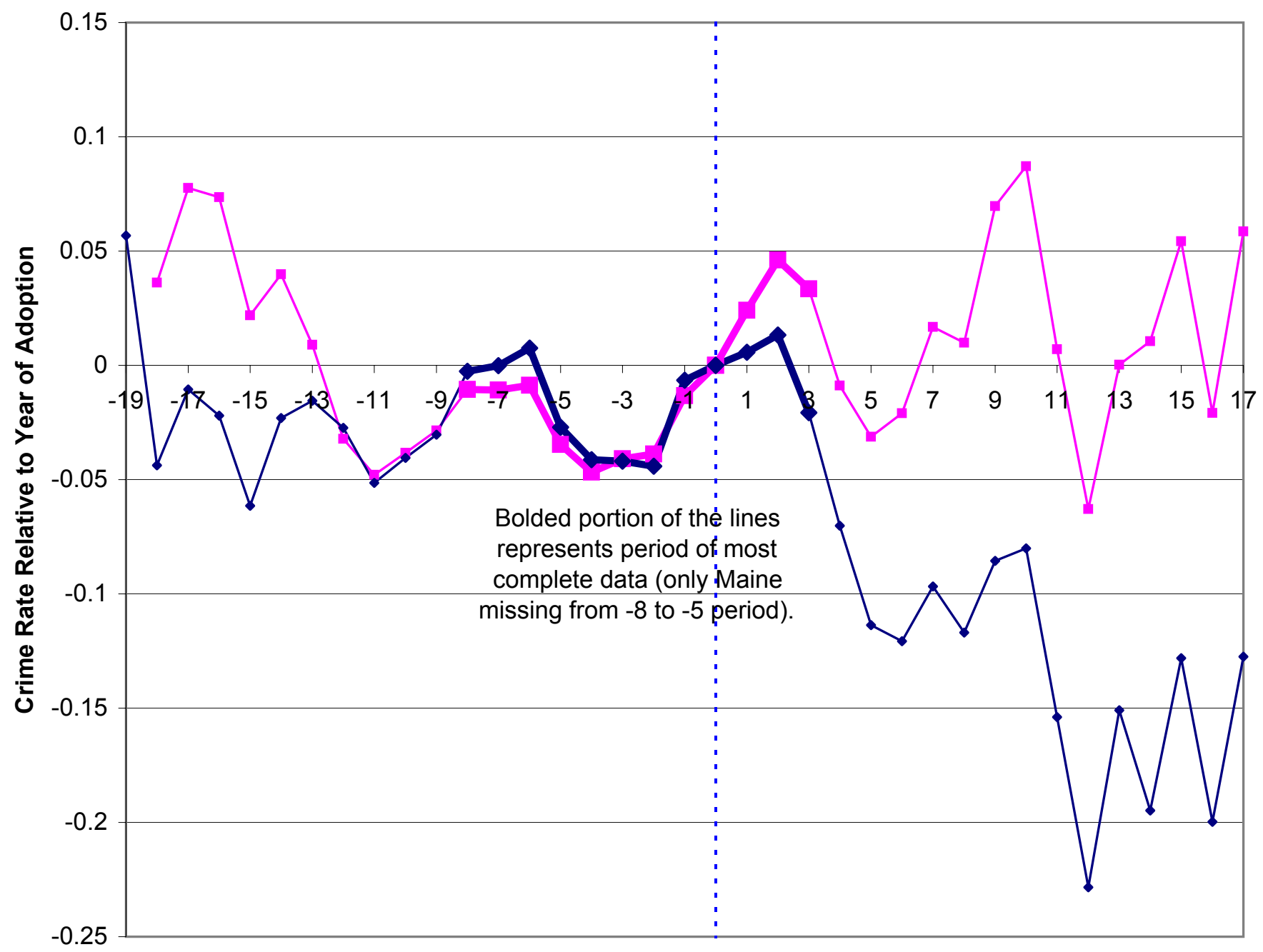

- Controlling for State Trends

$\longrightarrow$ Not Controlling for State Trends

- . . - - - Year of Adoption

Each value is the estimated coefficient (normalized to zero in the year of adoption) on a dummy variable for each year relative to shall-issue adoption in our standard panel data regression with state and year fixed effects using state data for 1977-1999. 
Figure 1f: Property Crime - Normalized Effect by Year Relative to Adoption (Vernick Coding)

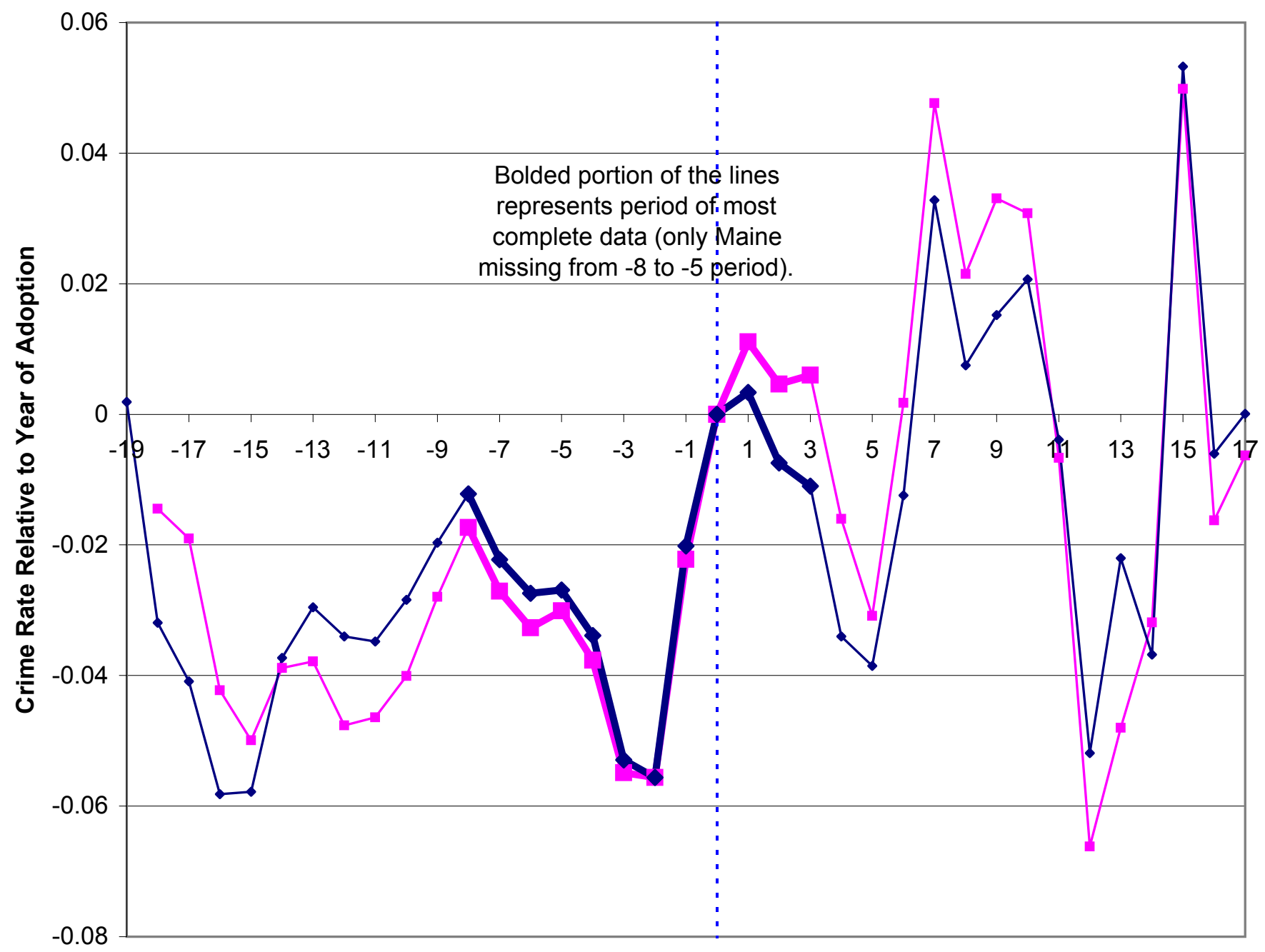
Controlling for State
Trends

$\longrightarrow$ Not Controlling for State Trends

- . - . - Year of Adoption

Each value is the

estimated coefficient (normalized to zero in the year of adoption) on a dummy variable for each year relative to shall-issue adoption in our standard panel data regression with state and year fixed effects using state data for 1977-1999.

Year Relative to Shall Adoption 
Figure 1g: Auto Theft - Normalized Effect by Year Relative to Adoption (Vernick Coding)
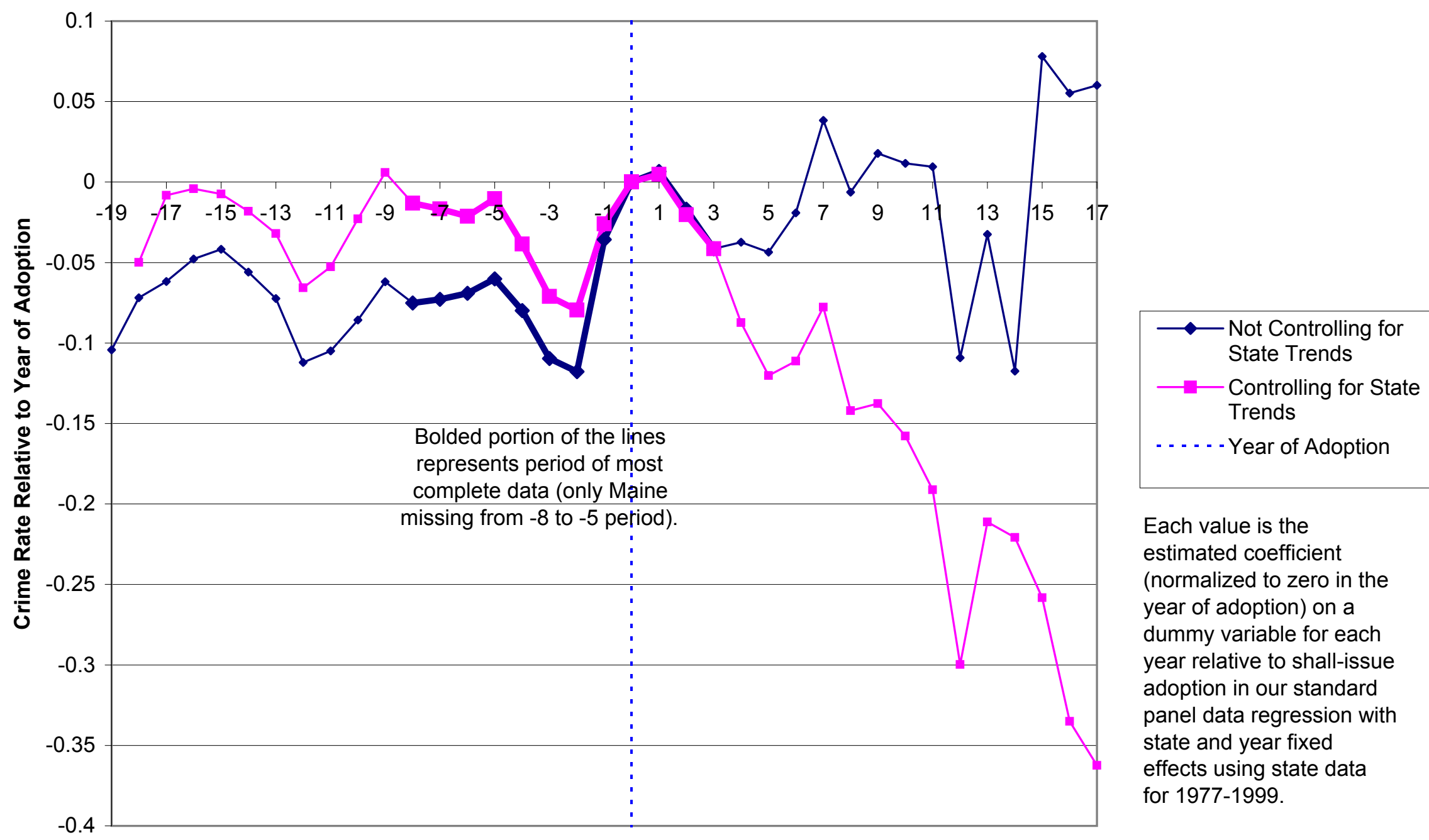

Each value is the estimated coefficient (normalized to zero in the year of adoption) on a dummy variable for each year relative to shall-issue adoption in our standard panel data regression with state and year fixed effects using state data for 1977-1999. 
Figure 1h: Burglary - Normalized Effect by Year Relative to Adoption (Vernick Coding)

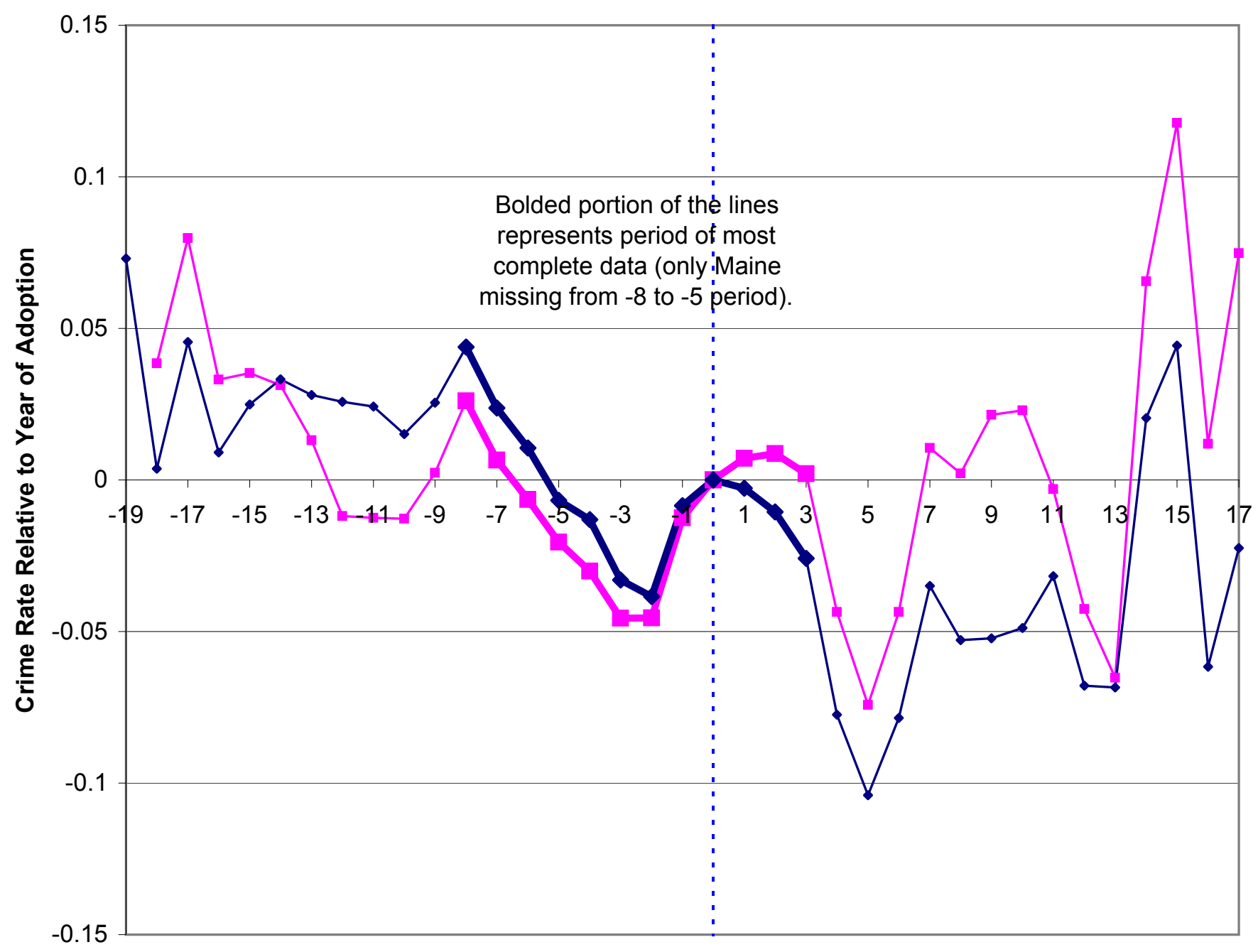

- Controlling for State Trends

$\longrightarrow$ Not Controlling for State Trends

.....- Year of Adoption

Each value is the estimated coefficient (normalized to zero in the year of adoption) on a dummy variable for each year relative to shall-issue adoption in our standard panel data regression with state and year fixed effects using state data for 1977-1999. 
Figure 1i: Larceny - Normalized Effect by Year Relative to Adoption (Vernick Coding)

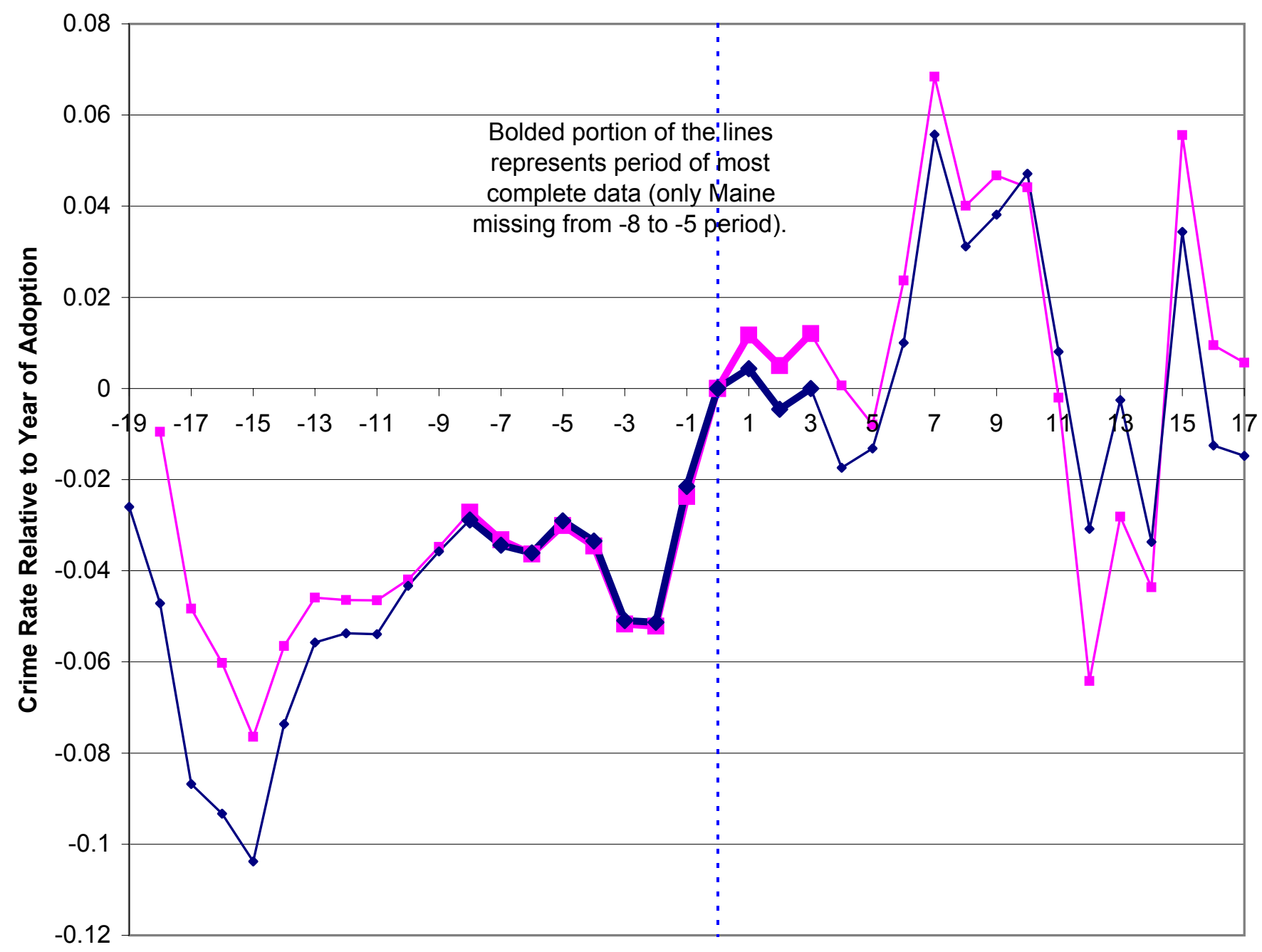

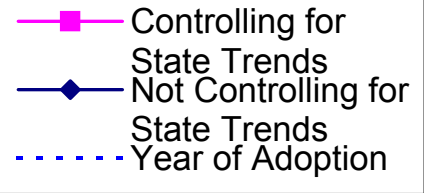

Each value is the estimated coefficient (normalized to zero in the year of adoption) on a dummy variable for each year relative to shall-issue adoption in our standard panel data regression with state and year fixed effects using state data for 1977-1999. 
Table 1a

The Estimated Impact of Shall Issue Laws on Crime, State Data, Vernick's coding, using Incarceration Rates, dropping early legalizers

\begin{tabular}{|c|c|c|c|c|c|c|c|c|c|}
\hline & $\begin{array}{l}\text { Violent } \\
\text { Crime }\end{array}$ & Murder & Rape & $\begin{array}{c}\text { Aggravated } \\
\text { Assault }\end{array}$ & Robbery & $\begin{array}{c}\text { Property } \\
\text { Crime }\end{array}$ & $\begin{array}{l}\text { Auto } \\
\text { Theft }\end{array}$ & Burglary & Larceny \\
\hline \multicolumn{10}{|l|}{ Time Period (1977-1999): } \\
\hline $\begin{array}{l}\text { 1. Dummy Variable model: } \\
\text { Robust Std. Error: }\end{array}$ & $\frac{4.2 \%}{(2.3 \%)}$ & $\begin{array}{l}\mathbf{5 . 9 \%} \\
(2.9 \%)\end{array}$ & $\begin{array}{c}2.9 \% \\
(2.3 \%)\end{array}$ & $\begin{array}{c}0.0 \% \\
(3.2 \%)\end{array}$ & $\frac{\mathbf{1 2 . 1 \%}}{(2.7 \%)}$ & $\frac{4.7 \%}{(1.5 \%)}$ & $\frac{\mathbf{1 1 . 8 \%}}{(3.2 \%)}$ & $\frac{3.4 \%}{(1.9 \%)}$ & $\begin{array}{l}3.7 \% \\
(1.6 \%)\end{array}$ \\
\hline $\begin{array}{l}\text { 2. Lott-Spline model: } \\
\text { Robust Std. Error: }\end{array}$ & $\begin{array}{c}0.9 \% \\
(1.0 \%)\end{array}$ & $\begin{array}{c}\mathbf{2 . 6 \%} \\
(1.3 \%)\end{array}$ & $\begin{array}{l}-1.4 \% \\
(1.0 \%)\end{array}$ & $\begin{array}{l}-0.2 \% \\
(1.5 \%)\end{array}$ & $\frac{3.2 \%}{(1.1 \%)}$ & $\begin{array}{c}0.6 \% \\
(0.7 \%)\end{array}$ & $\frac{3.3 \%}{(1.2 \%)}$ & $\begin{array}{c}0.3 \% \\
(0.9 \%)\end{array}$ & $\begin{array}{c}0.0 \% \\
(0.8 \%)\end{array}$ \\
\hline $\begin{array}{l}\text { 3. Hybrid model: } \\
\text { Post-Passage Dummy } \\
\text { Robust Std. Error: } \\
\text { Trend Effect } \\
\text { Robust Std. Error: }\end{array}$ & $\begin{array}{c}2.6 \% \\
(3.6 \%) \\
0.2 \% \\
(1.5 \%) \\
\end{array}$ & $\begin{array}{c}5.4 \% \\
(4.9 \%) \\
1.3 \% \\
(1.9 \%) \\
\end{array}$ & $\begin{array}{c}3.1 \% \\
(3.5 \%) \\
-2.2 \% \\
(1.5 \%) \\
\end{array}$ & $\begin{array}{c}-3.3 \% \\
(5.0 \%) \\
0.7 \% \\
(2.2 \%) \\
\end{array}$ & $\begin{array}{c}\underline{\mathbf{1 2 . 6 \%}} \\
(4.2 \%) \\
0.0 \% \\
(1.4 \%) \\
\end{array}$ & $\begin{array}{c}\underline{7.2 \%} \\
(2.5 \%) \\
-1.2 \% \\
(0.9 \%) \\
\end{array}$ & $\begin{array}{c}\mathbf{1 1 . 7 \%} \\
(5.2 \%) \\
0.3 \% \\
(1.6 \%) \\
\end{array}$ & $\begin{array}{c}\mathbf{7 . 5 \%} \\
(2.9 \%) \\
-1.6 \% \\
(1.1 \%) \\
\end{array}$ & $\begin{array}{c}\mathbf{5 . 7 \%} \\
(2.4 \%) \\
-1.4 \% \\
(1.0 \%) \\
\end{array}$ \\
\hline
\end{tabular}

Table $1 b$

The Estimated Impact of Shall Issue Laws on Crime Controlling for State Trends, State Data, Vernick's coding, using Incarceration Rates, dropping early legalizers

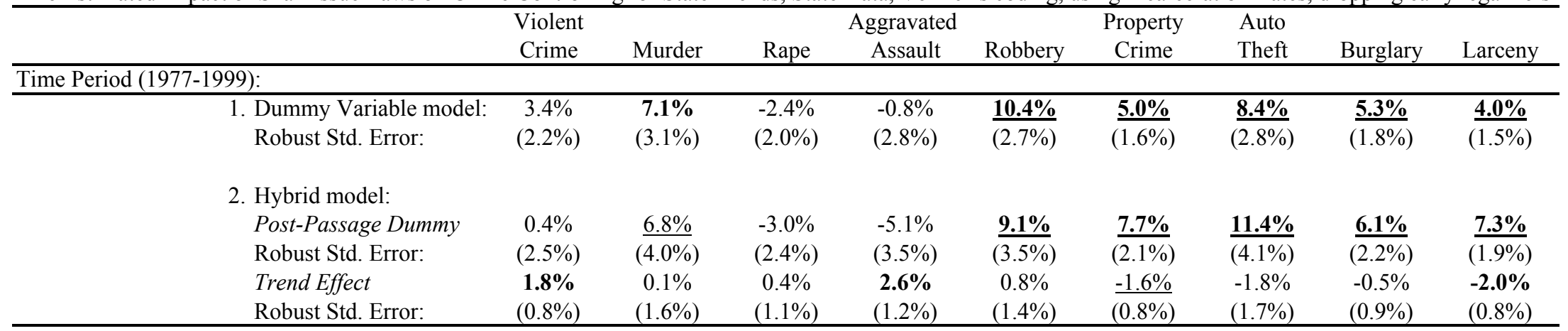

Notes: The dependent variable is the $\ln$ (crime rate) named at the top of each column. The data set is comprised of annual state-level observations (including the District of Columbia). State- and year- fixed effects are included in all specifications. All regressions are weighted by state population. Standard errors (in parentheses) are computed using the Huber-White robust estimate of variance. Coefficients that are significant at the .10 level are underlined. Coefficients that are significant at the .05 level are displayed in bold. Coefficients that are significant at the .01 level are both underlined and displayed in bold. "Early legalizer" is defined as a state passing a shall-issue law between 1977 and 1992 (as coded by Vernick). 
Table 2

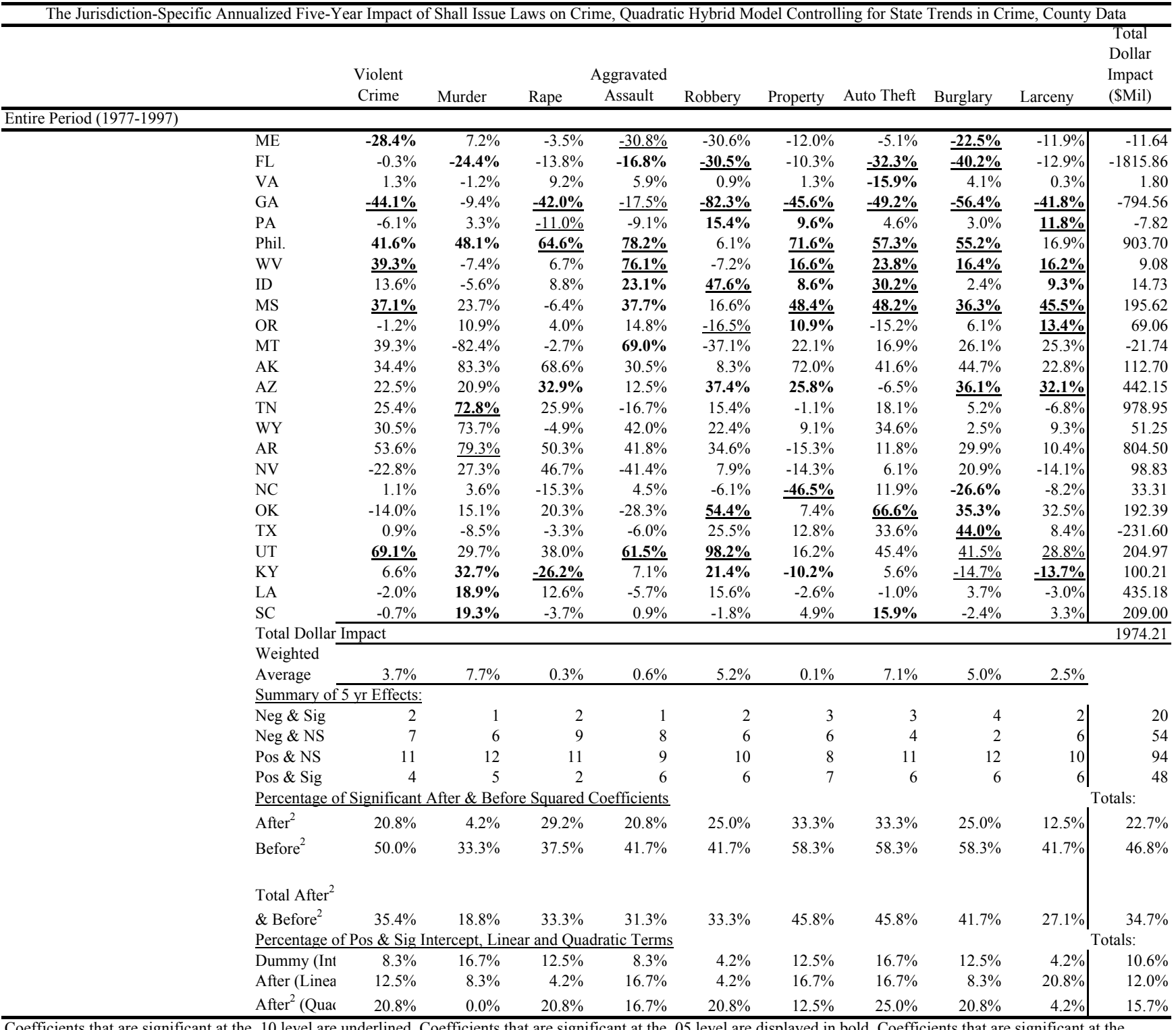

Coefficients that are significant at the .10 level are underlined. Coefficients that are significant at the .05 level are displayed in bold. Coefficients that are significant at the

.01 level are both underlined and displayed in bold. 
Table 3a - Replication of LPW's Table 3a

The Estimated Impact of Shall Issue Laws on Crime, County Data, Lott coding - with region-year effects

\begin{tabular}{|c|c|c|c|c|c|c|c|c|c|}
\hline \multirow[b]{2}{*}{ Entire Period (1977-2000): } & \multicolumn{2}{|l|}{ Violent } & \multicolumn{3}{|c|}{ Aggravated } & \multirow{2}{*}{$\begin{array}{c}\text { Property } \\
\text { Crime }\end{array}$} & \multirow{2}{*}{$\begin{array}{l}\text { Auto } \\
\text { Theft }\end{array}$} & \multirow[b]{2}{*}{ Burglary } & \multirow[b]{2}{*}{ Larceny } \\
\hline & Crime & Murder & Rape & Assault & Robbery & & & & \\
\hline $\begin{array}{l}\text { 1. Dummy Variable model: } \\
\text { Robust Std. Error: }\end{array}$ & $\begin{array}{l}-2.8 \% \\
(4.1 \%)\end{array}$ & $\begin{array}{l}-\mathbf{6 . 2 \%} \\
(3.1 \%)\end{array}$ & $\begin{array}{l}-6.5 \% \\
(2.6 \%)\end{array}$ & $\begin{array}{l}-1.6 \% \\
(4.8 \%)\end{array}$ & $\frac{-5.4 \%}{(3.1 \%)}$ & $\begin{array}{l}4.1 \% \\
(2.6 \%)\end{array}$ & $\begin{array}{l}\mathbf{9 . 0} \% \\
(4.4 \%)\end{array}$ & $\begin{array}{c}0.4 \% \\
(2.2 \%)\end{array}$ & $\frac{\mathbf{6 . 0 \%}}{(2.3 \%)}$ \\
\hline \multicolumn{10}{|l|}{ 2. Lott-Spline model: } \\
\hline Trend before & $0.2 \%$ & $0.4 \%$ & $0.6 \%$ & $0.6 \%$ & $0.6 \%$ & $0.8 \%$ & $1.1 \%$ & $\underline{0.9 \%}$ & $\underline{1.1 \%}$ \\
\hline Robust Std. Error: & $(0.4 \%)$ & $(0.5 \%)$ & $(0.4 \%)$ & $(0.6 \%)$ & $(0.7 \%)$ & $(0.3 \%)$ & $(0.5 \%)$ & $(0.5 \%)$ & $(0.4 \%)$ \\
\hline Trend after & $-0.5 \%$ & $-2.0 \%$ & $-2.3 \%$ & $-1.3 \%$ & $\underline{-2.0 \%}$ & $0.7 \%$ & $0.7 \%$ & $-1.1 \%$ & $0.2 \%$ \\
\hline Robust Std. Error: & $(0.7 \%)$ & $(0.9 \%)$ & $(0.8 \%)$ & $(1.0 \%)$ & $(0.8 \%)$ & $(0.5 \%)$ & $(0.5 \%)$ & $(0.7 \%)$ & $(0.9 \%)$ \\
\hline Difference between trenc & -0.007 & -0.024 & -0.029 & -0.019 & -0.026 & -0.001 & -0.004 & -0.02 & -0.009 \\
\hline$\underline{\text { Prob }>F}$ & $27.1 \%$ & $5.5 \%$ & $0.9 \%$ & $9.7 \%$ & $4.3 \%$ & $86.6 \%$ & $52.7 \%$ & $7.2 \%$ & $44.1 \%$ \\
\hline \multicolumn{10}{|l|}{ 3. Hybrid model: } \\
\hline Trend before & $0.2 \%$ & $0.4 \%$ & $0.5 \%$ & $0.5 \%$ & $0.7 \%$ & $\underline{0.9 \%}$ & $\underline{0.9 \%}$ & $0.7 \%$ & $\underline{1.0 \%}$ \\
\hline Robust Std. Error: & $(0.4 \%)$ & $(0.4 \%)$ & $(0.4 \%)$ & $(0.5 \%)$ & $(0.7 \%)$ & $(0.3 \%)$ & $(0.5 \%)$ & $(0.5 \%)$ & $(0.3 \%)$ \\
\hline Post-Passage Dummy & $-2.6 \%$ & $-0.7 \%$ & $0.7 \%$ & $3.1 \%$ & $-0.2 \%$ & $-1.4 \%$ & $6.2 \%$ & $3.7 \%$ & $4.3 \%$ \\
\hline Robust Std. Error: & $(3.6 \%)$ & $(5.0 \%)$ & $(3.8 \%)$ & $(6.1 \%)$ & $(6.0 \%)$ & $(2.7 \%)$ & $(7.8 \%)$ & $(5.1 \%)$ & $(4.1 \%)$ \\
\hline Trend After & $-0.2 \%$ & $-1.9 \%$ & $-2.4 \%$ & $-1.7 \%$ & $-2.0 \%$ & $0.9 \%$ & $0.1 \%$ & $-1.5 \%$ & $-0.3 \%$ \\
\hline Robust Std. Error: & $(0.7 \%)$ & $(1.3 \%)$ & $(1.1 \%)$ & $(1.4 \%)$ & $(1.2 \%)$ & $(0.6 \%)$ & $(1.0 \%)$ & $(1.1 \%)$ & $(1.3 \%)$ \\
\hline Difference between trenc & -0.004 & -0.023 & -0.029 & -0.022 & -0.027 & 0 & -0.008 & -0.022 & -0.013 \\
\hline Prob $>F$ & $51.8 \%$ & $11.9 \%$ & $2.1 \%$ & $14.0 \%$ & $8.0 \%$ & $99.2 \%$ & $38.7 \%$ & $8.9 \%$ & $40.5 \%$ \\
\hline
\end{tabular}

Table $3 \mathrm{~b}$ - Correction of LPW's Table 3a (correcting region-year dummy errors and Massachussetts shall dummy coding errors) The Estimated Impact of Shall Issue Laws on Crime, County Data, Lott coding - with region-year effects

\begin{tabular}{|c|c|c|c|c|c|c|c|c|c|}
\hline \multirow[b]{2}{*}{ Entire Period (1977-2000): } & \multicolumn{3}{|l|}{ Violent } & \multicolumn{2}{|c|}{ Aggravated } & \multirow{2}{*}{$\begin{array}{l}\text { Property } \\
\text { Crime }\end{array}$} & \multirow{2}{*}{ Auto } & \multirow[b]{2}{*}{ Burglary } & \multirow[b]{2}{*}{ Larceny } \\
\hline & Crime & Murder & Rape & Assault & Robbery & & & & \\
\hline $\begin{array}{l}\text { 1. Dummy Variable model: } \\
\text { Robust Std. Error: }\end{array}$ & $\begin{array}{l}-0.4 \% \\
(4.5 \%)\end{array}$ & $\begin{array}{l}-4.2 \% \\
(3.3 \%)\end{array}$ & $\begin{array}{l}-4.8 \% \\
(3.2 \%)\end{array}$ & $\begin{array}{c}0.8 \% \\
(5.3 \%)\end{array}$ & $\begin{array}{l}-3.0 \% \\
(3.4 \%)\end{array}$ & $\begin{array}{c}\mathbf{6 . 1 \%} \\
(2.9 \%)\end{array}$ & $\begin{array}{l}11.0 \% \\
(4.5 \%)\end{array}$ & $\begin{array}{l}1.8 \% \\
(2.3 \%)\end{array}$ & $\frac{\mathbf{8 . 0 \%}}{(2.8 \%)}$ \\
\hline \multicolumn{10}{|l|}{ 2. Lott-Spline model: } \\
\hline Trend before & $0.3 \%$ & $0.5 \%$ & $0.7 \%$ & $0.7 \%$ & $0.8 \%$ & $\underline{0.9 \%}$ & $1.2 \%$ & $\underline{1.0 \%}$ & $1.2 \%$ \\
\hline Robust Std. Error: & $(0.4 \%)$ & $(0.5 \%)$ & $(0.5 \%)$ & $(0.6 \%)$ & $(0.7 \%)$ & $(\overline{0.3 \%)}$ & $(0.5 \%)$ & $(\overline{0.5 \%})$ & $\overline{(0.4 \%)}$ \\
\hline Trend after & $0.4 \%$ & $-1.0 \%$ & $-1.4 \%$ & $-0.3 \%$ & $-0.9 \%$ & $1.3 \%$ & $1.4 \%$ & $-0.4 \%$ & $0.9 \%$ \\
\hline Robust Std. Error: & $(0.9 \%)$ & $(1.0 \%)$ & $(1.0 \%)$ & $(1.2 \%)$ & $(1.0 \%)$ & $(0.6 \%)$ & $(0.7 \%)$ & $(0.8 \%)$ & $(1.0 \%)$ \\
\hline Difference between trenc & 0.001 & -0.015 & -0.021 & -0.01 & -0.017 & 0.004 & 0.002 & -0.014 & -0.003 \\
\hline Prob $>F$ & $88.0 \%$ & $26.0 \%$ & $10.3 \%$ & $47.5 \%$ & $29.5 \%$ & $60.1 \%$ & $77.1 \%$ & $23.0 \%$ & $81.1 \%$ \\
\hline \multicolumn{10}{|l|}{ 3. Hybrid model: } \\
\hline Trend before & $0.5 \%$ & $0.7 \%$ & $\underline{0.7 \%}$ & $0.7 \%$ & $0.9 \%$ & $1.0 \%$ & $1.1 \%$ & $\underline{0.9 \%}$ & $1.1 \%$ \\
\hline Robust Std. Error: & $(0.4 \%)$ & $(0.4 \%)$ & $(0.4 \%)$ & $(0.6 \%)$ & $(0.7 \%)$ & $(0.3 \%)$ & $(0.5 \%)$ & $(0.5 \%)$ & $(0.4 \%)$ \\
\hline Post-Passage Dummy & $-5.6 \%$ & $-3.9 \%$ & $-2.3 \%$ & $-0.2 \%$ & $-3.7 \%$ & $-3.4 \%$ & $3.5 \%$ & $1.3 \%$ & $1.9 \%$ \\
\hline Robust Std. Error: & $(3.7 \%)$ & $(4.8 \%)$ & $(3.4 \%)$ & $(5.6 \%)$ & $(5.6 \%)$ & $(2.9 \%)$ & $(7.4 \%)$ & $(5.1 \%)$ & $(3.8 \%)$ \\
\hline Trend After & $1.0 \%$ & $-0.6 \%$ & $-1.2 \%$ & $-0.2 \%$ & $-0.5 \%$ & $1.6 \%$ & $1.1 \%$ & $-0.5 \%$ & $0.7 \%$ \\
\hline Robust Std. Error: & $(1.0 \%)$ & $(1.3 \%)$ & $(1.2 \%)$ & $(1.5 \%)$ & $(1.3 \%)$ & $(0.7 \%)$ & $(1.1 \%)$ & $(1.1 \%)$ & $(1.3 \%)$ \\
\hline Difference between trenc & 0.005 & -0.013 & -0.019 & -0.009 & -0.014 & 0.006 & 0 & -0.014 & -0.004 \\
\hline Prob $>F$ & $61.7 \%$ & $41.4 \%$ & $16.8 \%$ & $54.9 \%$ & $42.1 \%$ & $45.7 \%$ & $98.7 \%$ & $27.7 \%$ & $77.6 \%$ \\
\hline
\end{tabular}

